\title{
Intestinal Necrotic Lesion
}

National Cancer Institute

\section{Source}

National Cancer Institute. Intestinal Necrotic Lesion. NCI Thesaurus. Code C78368.

A necrotic process involving the intestinal wall. 